OPEN ACCESS

Edited by:

Diana Dudziak

Universitätsklinikum Erlangen,

Germany

Reviewed by:

E. Ashley Moseman,

National Institute of Neurological

Disorders and Stroke (NINDS),

United States

Reinhard Obst

Ludwig-Maximilians-Universität

München, Germany

*Correspondence:

Joke M. M. den Haan

j.denhaan@vumc.nl

${ }^{\dagger}$ These authors share first authorship

Specialty section:

This article was submitted to Antigen Presenting Cell Biology,

a section of the journal

Frontiers in Immunology

Received: 26 July 2018 Accepted: 05 October 2018

Published: 26 October 2018

Citation

Grabowska J, Lopez-Venegas MA, Affandi AJ and den Haan JMM (2018) CD169+ Macrophages Capture and Dendritic Cells Instruct: The Interplay of the Gatekeeper and the General of the Immune System.

Front. Immunol. 9:2472. doi: 10.3389/fimmu.2018.02472

\section{CD169+ Macrophages Capture and Dendritic Cells Instruct: The Interplay of the Gatekeeper and the General of the Immune System}

\author{
Joanna Grabowska ${ }^{\dagger}$, Miguel A. Lopez-Venegas ${ }^{\dagger}$, Alsya J. Affandi and \\ Joke M. M. den Haan* \\ Department of Molecular Cell Biology and Immunology, Amsterdam University Medical Center, Cancer Center Amsterdam, \\ Amsterdam Infection and Immunity Institute, Vrije Universiteit Amsterdam, Amsterdam, Netherlands
}

Since the seminal discovery of dendritic cells (DCs) by Steinman and Cohn in 1973, there has been an ongoing debate to what extent macrophages and DCs are related and perform different functions. The current view is that macrophages and DCs originate from different lineages and that only DCs have the capacity to initiate adaptive immunity. Nevertheless, as we will discuss in this review, lymphoid tissue resident CD169+ macrophages have been shown to act in concert with DCs to promote or suppress adaptive immune responses for pathogens and self-antigens, respectively. Accordingly, we propose a functional alliance between $\mathrm{CD} 169^{+}$macrophages and DCs in which a division of tasks is established. CD169+ macrophages are responsible for the capture of pathogens and are frequently the first cell type infected and thereby provide a confined source of antigen. Subsequently, cross-presenting DCs interact with these antigen-containing $\mathrm{CD}_{169}{ }^{+}$macrophages, pick up antigens and activate $\mathrm{T}$ cells. The cross-priming of $T$ cells by DCs is enhanced by the localized production of type I interferons (IFN-I) derived from CD169+ macrophages and plasmacytoid DCs (pDCs) that induces DC maturation. The interaction between CD169+ macrophages and DCs appears not only to be essential for immune responses against pathogens, but also plays a role in the induction of self-tolerance and immune responses against cancer. In this review we will discuss the studies that demonstrate the collaboration between CD169+ macrophages and DCs in adaptive immunity.

Keywords: CD169, siglec-1, sialoadhesin, macrophages, dendritic cells, T cell, antigen, cross-presentation

\section{INTRODUCTION}

While the first recognized characteristic of macrophages was their excellent capacity to phagocytose, dendritic cells (DCs) were acknowledged for their superior ability to stimulate naïve $\mathrm{T}$ cell responses. However, ever since tissue macrophages and DCs showed overlapping expression of several markers and were both generated from monocytes in in vitro models, it has been debated whether these cell types were closely related and had equivalent functions. The introduction of unbiased single cell multi-parameter analyses on the protein and RNA level, and the 
generation of cell-type specific and inducible genetically modified mouse models has enabled a new understanding of the generation and functions of both macrophages and DCs, and has even led to a new nomenclature (1). The current view is that the two cell types have very different functions in the immune system. However, this viewpoint potentially overlooks functional collaborations between the two cell types. In this review we will focus on the interactions between lymphoid tissue resident CD169 ${ }^{+}$macrophages and DCs and how these support the activation of adaptive immune responses.

\section{DCs and Macrophages Are Different Cell Types With Different Functions}

The generation of macrophages is dependent on the growth factor M-CSF and occurs in three waves [reviewed by $(2,3)$ ]. First, during early embryonic development, yolk sac-derived progenitors seed several peripheral tissues, such as the brain and the epidermis. A second wave of progenitors derive from the fetal liver and seed lungs and liver. These two types of macrophages are characterized by high expression of F4/80 and in general reconstitute autonomously. Additionally, they are thought to have a long half-life and exhibit local proliferation. After birth, monocytes develop from hematopoietic stem cells in the bone marrow and tissues, such as the intestines and the skin that continuously receive monocytes to generate macrophages. The latter macrophages generally express low levels of F4/80.

Macrophages form a very heterogeneous population of cells and their diversity in phenotype and function is a reflection of the variety of the tissues in which they reside [reviewed by $(4,5)]$. They are best known for their capacity to phagocytose and eliminate pathogens and to alarm the immune system. In addition to this important function in immunosurveillance, they are essential for the clearance of apoptotic cells and suppression of (auto) immune responses and mediate resolution of inflammatory responses and tissue repair. Furthermore, depending on their tissue of residence, macrophages have important specialized functions in development, homeostasis and metabolism [discussed in more detail in $(4,6)$ ]. The general view is that macrophages exert their functions locally in the tissues and that in steady state tissue resident macrophages do not migrate to secondary lymph nodes to activate naïve $\mathrm{T}$ cells. This latter function is attributed to DCs that also reside in tissues, but upon pathogen recognition, upregulate CCR7 and travel to the lymphoid organs. However, upon inflammation monocytederived macrophages or DCs may also acquire the capacity to travel to the lymph nodes and stimulate T cells, which is a matter that has to be further clarified (7).

Currently, three types of DCs are being recognized [reviewed by $(8,9)$ ]. Conventional or classical DCs (cDCs) are continuously generated in the bone marrow and require Flt3L for their generation. Pre-cDCs seed the tissues and the lymphoid organs and have a half-life of 5-7 days. Upon activation and upregulation of CCR7, tissue cDCs migrate to the lymph nodes and can activate $\mathrm{T}$ cells. Within $\mathrm{cDC}$ s two subsets can be identified. The cDC1 is more specialized in the uptake of dying cells, crosspresentation and activation of $\mathrm{CD}^{+} \mathrm{T}$ cells, while $\mathrm{cDC} 2$ has a more important role in $\mathrm{CD}^{+}{ }^{+} \mathrm{T}$ cell activation and $\mathrm{B}$ cell responses. The generation of these two subsets is dependent on different transcription factors. While $\mathrm{cDC} 1$ requires Batf3, Id 2 and Irf8, cDC2 development depends on Irf4 and RelB and requires additional Notch2 and vitamin A signals (10). With regard to the surface phenotype, $\mathrm{CDC} 1$ can be identified by XCR1 and CLEC9A, and additionally by CD8 $\alpha$ in lymphoid organs and by CD103 in peripheral tissues. On the other hand, $\operatorname{Sirp} \alpha$, $\mathrm{CD} 11 \mathrm{~b}$ and $\mathrm{CD} 4$ expression marks the $\mathrm{cDC} 2$ subset. Next to cDCs, pDCs form another class of DCs that also develop in a Flt3L-dependent manner. This lineage splits from the $\mathrm{cDC}$ lineage before the separation in $\mathrm{CDC} 1$ and $\mathrm{CDC} 2$. They can be identified by CD123, BDCA2, and BDCA4 in humans and by high expression of BST2 and Siglec-H and by low expression of CD11c and B220 in the mouse. Recent studies have indicated further heterogeneity in CD123-expressing pDCs $(11,12)$. While early studies indicate that pDCs can take up antigens and stimulate $\mathrm{T}$ cells upon activation, recent studies suggest that very pure $\mathrm{pDC}$ populations only produce IFN-I and are not able to activate $\mathrm{T}$ cells unless they are pre-treated with CD40L and IL-3 (13). This suggests a limited function for $\mathrm{pDC}$ in $\mathrm{T}$ cell activation.

Next to these two Flt3L-dependent DC subsets, DCs can differentiate from monocytes during inflammatory conditions (7). The function of these DCs in the regulation of adaptive immune responses remains to be elucidated.

\section{Antigen Cross-Presentation by Macrophages and Dendritic Cells}

Both macrophages and DCs process antigens via the classical endogenous and exogenous pathways and present these on their MHC class I and II molecules, respectively, but they differ in their capacity to cross-present exogenous antigens in MHC class I and to cross-prime CD8 ${ }^{+} \mathrm{T}$ cells. Cross-presentation was first described in 1976 by Bevan as the process in which $\mathrm{CD} 8^{+} \mathrm{T}$ cell responses were initiated against donor antigens restricted by recipient MHC molecules (14). This process is thought to be essential in the activation of anti-viral and anti-tumor specific $\mathrm{CD}^{+} \mathrm{T}$ cell responses. While a number of studies have shown that exogenous antigens can be cross-presented by different cell types including macrophages (15), the mouse cDC1 subset exhibits a higher capacity to cross-present and is especially equipped for the uptake of dead cells and the cross-presentation of cell-associated antigens (16-19). However, depending on the antigen and activation stimuli, mouse $\mathrm{CDC} 2$ and several human DC subsets are also able to cross-present $(17,20)$. There are two main routes of antigen processing exist that leads to crosspresentation. In the cytosolic route, antigens are transported from the endosomal/phagosomal pathway to the cytoplasm and this pathway depends on proteasomes and TAP. In the vacuolar route, antigens are degraded in the endosomal/phagosomal pathway and bind to recycling MHC class I molecules. This pathway relies on the activity of cathepsin S. DCs mainly utilize the cytosolic route, while macrophages and monocytederived DCs have been shown to use the vacuolar route of cross-presentation $(21,22)$. Recent studies have identified a 
number of molecules involved in vesicular trafficking that play a role in cross-presentation [see for more details reviews (15, $23,24)]$. One of the important factors for cross-presentation is the rate of antigen degradation. Macrophages are more proteolytically active than DCs, which impairs their capacity to cross-present (25). DCs prevent the acidification of their phagosomes and thereby inhibit proteolysis by the activity of NADPH oxidase 2 (NOX2) enzyme [reviewed in (26)]. The NOX2 enzyme may also contribute to the translocation of antigens to the cytosol by disrupting the phagosomal membrane. The longer preservation of antigens in DCs and stronger phagosome-cytotosol translocation compared to macrophages may be responsible for the more prominent role of DCs in cross-priming.

\section{Generation of CD169+ Macrophages and Their Innate Functions}

Macrophages expressing high levels of CD169, also known as Siglec-1 or sialoadheasin, constitute a minor macrophage population present in lymphoid tissues $(27,28)$. While several macrophage populations in tissues have low levels of CD169, which can be upregulated upon exposure to IFN-I, this lymphoid resident population has a very high constitutive expression of $\mathrm{CD} 169$. $\mathrm{CD} 169^{+}$macrophages are situated on top of $B$ cell follicles bordering the marginal sinus in the spleen and the subcapsular sinus (SCS) in the lymph nodes and are also known as metallophilic marginal zone macrophages and SCS macrophages, respectively. The presence of B cells is necessary for the generation of $\mathrm{CD} 69^{+}$macrophages, which is mediated by their production of $\operatorname{LT} \alpha 1 \beta 2(29,30)$. In addition, they require RANK, LXR, and M-CSF signals and their survival is further promoted by TNF- $\alpha$ (31-34). Currently it is unclear which precursor gives rise to $\mathrm{CD} 169^{+}$ macrophages, although their low level of F4/80 expression would suggest that they are not derived from yolk sac precursors. After elimination, they are repopulated from monocytes (34).

The strategic position of $\mathrm{CD} 69^{+}$macrophages at the entry site of lymphoid tissues determines their function. CD169 ${ }^{+}$ macrophages are the first cell type in the spleen and lymph nodes to bind particulate antigens and pathogens and they function as a filter to remove foreign particles from the lymph fluid and blood. When these cells are deleted by clodronate liposomes in an experimental setting, pathogens can disseminate to other organs as has been demonstrated for several viral, bacterial and parasitic infections (35-39). This particular observation coined the term "gatekeeper" to describe CD169 ${ }^{+}$macrophages. This first line of defense, capturing invading viruses and limiting their spread to other organs, is not only mediated via the physical binding and capture of pathogens. $\mathrm{CD} 169^{+}$macrophages also exert their protective functions by the production of cytokines, such as IFN-I, IL-1, and IL-18. This cytokine secretion not only prevents subsequent infection of other cells and activates innate lymphocytes that help to contain the early infection (40-42), but also acts on DCs and stimulate adaptive immune responses.

\section{Model Systems to Study CD169+ Macrophages}

Due to their low abundance and sensitivity to manipulation, $\mathrm{CD}_{169^{+}}$macrophages are quite an enigmatic and technically challenging subset to study. Although it is feasible to extract these cells from spleen or lymph nodes by combination of mechanistic dissociation and enzymatic digestion, they rapidly die and form apoptotic blebs that bind to interacting cells (41, $43,44)$. This feature greatly hampers the purification of CD169+ macrophages using fluorescence-activated cell sorting (FACS) for in vitro analysis. Unfortunately, available in vitro models do not offer a satisfactory method to investigate this macrophage population. In vitro cultured macrophages can be treated with IFN- $\alpha$, which induces CD169 expression on the cell surface, but it is not clear whether these cells exhibit other characteristics of the CD169 ${ }^{+}$macrophages present in vivo. Most studies investigating $\mathrm{CD}_{169}{ }^{+}$macrophages take advantage of cell ablation tools, either chemical using clodronate liposomes or genetic using diphtheria toxin receptor (DTR) systems. Despite representing a very effective method for transient depletion of macrophages, clodronate liposomes lack specificity. This apoptosis-inducing agent is toxic for all phagocytosing cells including monocytes and DCs (45). Noteworthy, the treatment with clodronate liposomes affects the anatomy of the surrounding tissue and induces off-target effects on B cells (46). In comparison to clodronate liposomes, DTR-mediated cell ablation allows for conditional and targeted depletion of a cell subset engineered to express DTR. CD11c-DTR and CD169-DTR are two DTR transgenic mouse strains that deplete $\mathrm{CD} 169^{+}$macrophages $(47,48)$. Although the CD11c-DTR model mainly depletes cells with high expression of CD11c, thus DCs, it does not spare macrophages that express low levels of this DC marker (49). The CD169-DTR model, on the other hand provides a more specific approach to study $\mathrm{CD} 169^{+}$macrophages, leaving the DC population unaffected. The only other population affected by DT treatment in CD169-DTR model, are SIGN-R1 ${ }^{+}$marginal zone macrophages that express low levels of CD169 (47). Similarly, the LXR- $\alpha$ KO lack both $\mathrm{CD}_{169^{+}}$and SIGNR1 ${ }^{+}$splenic marginal zone macrophage subsets (34). More recently, CD169-Cre mice have been generated and when crossed to the ROSA26-YFP mice generate reporter mice (50). The CD169-Cre mice will allow the generation of CD169-specific conditional $\mathrm{KO}$ mice and is therefore expected to provide a wealth of new insights for this macrophage population.

\section{CD169+ MACROPHAGES AND IFN-I PRODUCTION}

Upon encounter with pathogens, such as viruses, CD169 ${ }^{+}$ macrophages regulate pathogen spread and induce immune responses by producing IFN-I. IFN-I consist of a single IFN- $\beta$ and several subtypes of IFN- $\alpha$, that signal through IFN-I receptor, a shared receptor expressed in almost all cell types (51). The importance of IFN-I signaling is 2-fold: (1) IFN-I can induce intracellular antiviral responses to suppress viral replication in the infected cells (52), and (2) IFN-I can regulate both innate and 
adaptive immune responses that are required to clear pathogens. However, depending on the type of pathogen, the outcome of IFN-I actions can play both protective and detrimental roles to the host $(53,54)$.

\section{Viral Infection of CD169+ Macrophages Results in IFN-I Production}

$\mathrm{CD}_{169}{ }^{+}$macrophages rapidly produce IFN-I after infection and thereby restrict the spread of a variety of viruses including mouse cytomegaloviruses (CMV), herpesvirus, and lymphocytic choriomeningitis virus (LCMV) (55-58). Several studies using neurotropic vesicular stomatitis virus (VSV) infection show that IFN-I signaling is necessary for the survival of the mice. Upon VSV infection, IFN-I was shown to be largely produced by $\mathrm{CD}_{169^{+}}$macrophages and this prevented VSV from entering the central nervous system (38). Similarly, during experimental infection with recombinant modified vaccinia virus Ankara (MVA), $\mathrm{CD} 69^{+}$macrophages were found to be the main IFN-I producers (59). In this model, CD169 ${ }^{+}$ macrophages recruited and activated NK cells upon MVA infection, which was dependent on the production of IFNI by $\mathrm{CD} 169^{+}$macrophages. Additionally, MVA infection also induced inflammasome activation by $\mathrm{CD}_{169^{+}}$macrophages that led to pyroptotic cell death, cytokine burst, and recruitment of inflammatory cells (60).

\section{CD169+ Macrophages Recruit and Prime IFN-I Production by pDCs}

Next to $\mathrm{CD} 169^{+}$macrophages, pDCs are well-known for their capacity to produce IFN-I. They express TLR7 and TLR9 and high basal levels of IRF7 that allows them to detect intracellular nucleic acids and to produce IFN- $\alpha$ immediately upon encounter with pathogens (61). pDCs are located mainly in the lymphoid organs, such as bone marrow, spleen, and lymph nodes, but not in non-lymphoid tissues. In steady state, pDCs can be found in the $\mathrm{T}$ cell zone and peri-follicular area of the lymph node. Upon infection with pathogens, such as VSV, pDCs migrate to the SCS and medulla, areas rich in $\mathrm{CD}_{169^{+}}$macrophages (38). pDCs were reported to account for half of the IFN-I produced upon VSV infection, which was dependent on the presence of CD169 ${ }^{+}$ macrophages. In a another study, the migration of pDCs to SCS was shown to be mediated by CXCR3, chemokine receptor of CXCL9, CXCL10, amongst others (62). It was suggested that viral particles from the infected $\mathrm{CD} 169^{+}$macrophages could activate these migrating pDCs. However, the direct interaction between SCS CD169 ${ }^{+}$macrophages and $\mathrm{pDCs}$ and its consequences are still unclear.

In a malaria infection model, pDCs accounted for the majority of IFN-I produced which led to lethal outcomes of infected mice (63). Spaulding et al. reported that after infection with malaria, $\mathrm{CD} 169^{+}$macrophages sustained prolonged interaction with pDCs in the bone marrow and primed them to produce IFN-I. Thus, this study provides evidence of an active interaction between $\mathrm{CD} 69^{+}$macrophages and $\mathrm{pDC}$ that may also occur in other lymphoid organs.

However, pDC-derived IFN-I may be dispensable in some situations. In a study that exploited an MCMV footpad infection model, pDC depletion using $\alpha$ BST2 antibodies led to an increase in MCMV escape from SCS and spread to other tissues (55). Nevertheless, this effect was moderate when compared to blocking IFN-I using anti-IFN-I receptor antibodies. In another MCMV model where MCMV was administered intraperitoneally, depletion of pDCs also resulted in an increase of viral spread and dissemination, but only when a low dose was used (64). pDCs were also demonstrated dispensable for survival of the mice upon infection with VSV and Plasmodium $(38,63)$. Thus, upon pathogen encounter by $\mathrm{CD}_{169}{ }^{+}$macrophages, $\mathrm{pDCs}$ are recruited to amplify IFN-I signaling, however this is not always essential for pathogen clearance or mice survival. Nevertheless, pDCderived IFN-I may still contribute to other aspects of immune responses.

\section{IFN-I Augments CDCs to Initiate Adaptive Immune Responses}

The initiation of adaptive immune response by $\mathrm{cDCs}$ involves multiple mechanisms including antigen presentation, costimulatory/inhibitory molecules, and immunomodulation by cytokines. Next to its role in inhibiting viral replication, IFN-I has been demonstrated to augment NK cell function, B cell isotype switching, and T cell survival and activation (65). IFN-I is also critical for the function of $\mathrm{cDCs}$ to fully activate naïve $\mathrm{T}$ cells as it stimulates the expression of co-stimulatory molecules, enhances responses to TLR-ligands and increases antigen presentation capacity (66-69). CDC1, in particular, require the presence of IFN-I for antigen cross-presentation and subsequent $\mathrm{CD}^{+} \mathrm{T}$ cell activation (70). Several reports have demonstrated IFN-activated $\mathrm{cDC} 1$ to be important for generating $\mathrm{CD} 8^{+} \mathrm{T}$ cell responses against tumor or viral infections (71-73). In fact, IFN-I signaling induced by viruses could enhance the development of $\mathrm{CD}^{+} \mathrm{T}$ cell-mediated anti-tumor responses as a vaccination strategy $(70,74,75)$.

Studies have been performed to identify the source of IFNI required for the maturation of $\mathrm{cDCs}$. In a vaccination system using tumor protein antigen and an iNKT cell ligand $\alpha$-GalCer, splenic pDCs produced high amounts of IFN-I (76). Importantly, prior to $\mathrm{CDC} 1$ trafficking to the white pulp for T cell stimulation, pDCs were found to cluster with $\mathrm{CDC} 1 \mathrm{~s}$ in the $\mathrm{CD} 169^{+}$ macrophage-rich marginal zone and red pulp area of the spleen. It was further shown that abolishing IFN-I signaling in $\mathrm{CD} 11 \mathrm{c}^{+}$ cells led to an impaired memory $\mathrm{T}$ cell formation. This was in line with a previous study, where $\mathrm{pDCs}$ were reported to promote the generation and survival of antigen-specific $\mathrm{CD} 8^{+} \mathrm{T}$ cells upon VSV infection (64). More recently, Brewitz and colleagues have demonstrated pDC-derived IFN-I to be important for CD8 ${ }^{+} \mathrm{T}$ cell activation by $\mathrm{cDC} 1$ when mice were exposed to MVA (62). After MVA infection, pDCs, cDC1s, and CD8 ${ }^{+} \mathrm{T}$ cells formed superclusters in the interfollicular area of the lymph node. This event was required for $\mathrm{CD}^{+} \mathrm{T}$ cell responses. Additionally, in a vaccination strategy using TLR7 agonist as an adjuvant, pDC-derived IFN-I was crucial for in vivo $\mathrm{CD} 8^{+} \mathrm{T}$ cell killing (77). These observations suggest an important cross-talk between IFN-I-producing $\mathrm{pDCs}$ and $\mathrm{CD} 8^{+} \mathrm{XCR}^{+}{ }^{\mathrm{cDC}} 1$ for an optimal $\mathrm{CD}^{+} \mathrm{T}$ cell activation in vaccination or viral infection. 
The effect of IFN-I derived from $\mathrm{CD} 169^{+}$macrophages and pDCs on the function of cDCs is not limited to $\mathrm{CD}^{+} \mathrm{T}$ cell activation. Upon infection with $S$. mansoni eggs, IFN-I was needed for an optimal $\mathrm{cDC}$ activation, migration and induction of Th2 immune responses in vivo (78). In a DC-targeting vaccination using HIV gag-protein and poly(I:C) as an adjuvant, $\mathrm{CD}^{+}{ }^{+}$Th1 responses were abolished upon interference with IFN-I signaling (79). Next to T cells, IFN-I signaling on DCs could also mediate B cell function including antibody production, isotype switching and the development of $\mathrm{T}$ follicular helper cells $(80,81)$. Thus, IFN-I stimulated DCs have an enhanced capacity to activate both humoral and cell-mediated adaptive immune responses.

A similar priming effect of IFN-I on cross-presentation has also been shown in human DCs $(82,83)$. In humans, the level of IFN-I is highly elevated and has been suggested to contribute to the break of tolerance in many autoimmune diseases (84). For example in systemic lupus erythematosus (SLE), the increased level of IFN-I produced by pDCs directly induced cDCs maturation and $\mathrm{CD} 4^{+} \mathrm{T}$ cell activation (85). In psoriasis, pDCderived IFN-I was sufficient to drive $\mathrm{T}$ cells infiltration and psoriatic plaque lesion formation (86). Interestingly, the numbers of CD169-expressing monocytes/macrophages were increased in the circulation and affected tissues of patients with systemic sclerosis and multiple sclerosis $(87,88)$. More investigation is needed to clarify the intricate cross-talk of $\mathrm{CD} 169^{+}$macrophage and pDC-derived IFN-I, cDC1, and T cell immunity in human diseases.

\section{Suppressive Effects of IFN-I}

Of note, the role of IFN-I during an infection is largely context-dependent and can also result in immunosuppression. A sustained IFN-I production can lead to increase of IL-10 and a higher expression of PD-L1. In a model of a persistent infection using LCMV strain Docile, upregulation of PD-L1 expression by $\mathrm{CD} 169^{+}$macrophages was important to promote $\mathrm{CD} 8^{+} \mathrm{T}$ cell exhaustion and prevented lethal immunopathology (58). The increased expression of PD-L1 in $\mathrm{CD}_{169^{+}}$macrophages was also observed in infection model with other LCMV strains (89). In addition, chronic infection with LCMV led to a sustained IFN-I production that prevented mice from mounting immune responses to a secondary infection by VSV (90). This was due to a reduced viral replication in $\mathrm{CD}_{169^{+}}$macrophages and subsequent impaired antigen presentation and lack of adaptive immune responses, rather than immunosuppression. However, using a model of $E$. coli-induced septic shock and subsequent systemic challenge with ovalbumin (OVA)-containing viruses, Schwandt et al. demonstrated that mice with sepsis had reduced antigen-specific $\mathrm{CD}^{+} \mathrm{T}$ cell responses. This suppression was mediated by macrophage-derived IFN-I that hampered $\mathrm{cDC} 1$ function to activate CD8 ${ }^{+} \mathrm{T}$ cells (91). Together these studies indicate that during chronic infections IFN-I production by $\mathrm{CD} 69^{+}$macrophages inhibits activation of immune responses toward secondary infections.

In conclusion, the production of IFN-I by $\mathrm{CD}_{169}+$ macrophages, potentially amplified by pDC-derived IFN-I, can strongly stimulate $\mathrm{cDC}$ function and the activation of immune responses, but may also result in immunosuppression.

\section{CD169+ MACROPHAGES EFFICIENTLY CAPTURE PATHOGENS AND MEDIATE ANTIGEN TRANSFER}

Their strategic location in spleen and in lymph nodes endows CD $169^{+}$macrophages with the capacity to capture blood- and lymph-borne pathogens. In fact, $\mathrm{CD} 169^{+}$macrophages appear to be extremely efficient in this process, as showed by multiple groups using various infection models (37, 38, 40, 92-96). Having acquired viral antigens, $\mathrm{CD} 169^{+}$macrophages were reported to transfer antigen to DCs and B cells mainly contributing to the infection control but also to virus dissemination in some cases.

\section{CD169+ Macrophages Enable Containment of Viral Infection and Localized Production of Antigen}

The role of $\mathrm{CD}_{169} 9^{+}$macrophages as efficient gatekeepers has been demonstrated in a large number of viral infections, such as adenovirus, vaccinia virus, West Nile virus, and VSV $(37,92,97)$. Additionally, experiments with human immunodeficiency virus (HIV) and murine leukemia virus (MLV) models confirmed prompt and potent virus capture by these gatekeeping macrophages (93). Deletion of splenic CD169 ${ }^{+}$ macrophages was reported to cause rapid dissemination of LCMV and herpes virus infection $(35,98)$. Along the same line, local depletion of SCS macrophages resulted in higher viral titers in the spleen and other organs providing direct evidence for the protective role of $\mathrm{CD} 169^{+}$macrophages in systemic viral spread $(37,38,40)(99)$. This clearly demonstrated the importance of $\mathrm{CD} 169^{+}$macrophages in infection containment.

Paradoxically, $\mathrm{CD} 169^{+}$macrophages can also support virus replication $(33,38,99)$. Enforced virus replication within $\mathrm{CD} 169^{+}$macrophages endowed them with the distinct feature of being a source of viral antigen that facilitated activation of adaptive immune responses. Accordingly, increased expression of inhibitory protein Usp18 rendered splenic $\mathrm{CD} 169^{+}$macrophages unresponsive to IFN-I. As a consequence, enhanced cytopathic VSV replication in these cells was facilitated (94). CD $169^{+}$macrophage-mediated VSV replication mediated a strong VSV-neutralizing antibody response that rescued infected animals. Positive correlation between viral replication in $\mathrm{CD}_{169^{+}}$macrophages and protective adaptive immune responses was also shown in LCMV infection (100).

\section{CD169+ Macrophages Transfer Antigens to DCs in Viral Infections}

Apart from effective viral capture and containment of the infection, $\mathrm{CD} 169^{+}$macrophages have been previously reported to directly present particulate antigens, immune complexes as well as intact virus particles to non-cognate and cognate B cells (37, 101-103). This process was shown to stimulate germinal center responses and production of high affinity antibodies $(103,104)$. While in these initial studies that used clodronate 
liposomes, B cells were still activated in the absence of SCS macrophages (38), a recent study indicated that absence of SCS macrophages led to defective $B$ cell responses (105). This process of intact virus presentation to $\mathrm{B}$ cells by $\mathrm{CD} 169^{+}$macrophages has also been implicated in trans-infection of B cells, contributing to the virus dissemination rather than to the virus containment (discussed in more detail in section CD169 as a viral receptor that mediates virus capture and trans-infection).

Despite robust evidence proving the importance of $\mathrm{CD} 169^{+}$ macrophages in the induction of anti-viral $\mathrm{B}$ cell responses, their role in the activation of $\mathrm{T}$ cell responses is still being elucidated. While a number of studies demonstrate that $\mathrm{CD} 169^{+}$ macrophages are dispensable for T cell priming $(35-38,94,97)$, interaction between $\mathrm{CD} 169^{+}$macrophages and $\mathrm{cDC} 1 \mathrm{~s}$ has been shown to promote anti-viral $\mathrm{T}$ cell responses $(44,106,107)$. The study by Backer et al. indicated that $\mathrm{CD} 169^{+}$macrophages could transfer antigens to $\mathrm{CDC1}$ s for the stimulation of CTL responses (106). In line with this, Bernhard et al. showed that antigen transfer between $\mathrm{CD} 169^{+}$macrophages and $\mathrm{cDCs}$ also occurred in adenoviral infection. Interestingly, CD169 ${ }^{+}$ macrophages were also able to directly present viral antigens to $\mathrm{T}$ cells bypassing the need for $\mathrm{cDCs}$ for $\mathrm{T}$ cell priming. While all epitopes, including low affinity peptides, were directly presented by $\mathrm{CD} 169^{+}$macrophages, $\mathrm{CDC} 1$ s only cross-presented high affinity $\mathrm{T}$ cell epitopes (107).

Recently, the collaboration between $\mathrm{CD} 169^{+}$and $\mathrm{cDC} 1 \mathrm{~s}$ was investigated in more detail (44). This study revealed that the CD169 receptor enabled cell-cell contact with sialylated ligands on cDCs and thereby facilitated transfer of antigen to cDCs. In addition to mediating adhesion to DCs, CD169 has also been reported to support binding of innate-like lymphocytes and neutrophils $(41,108,109)$. Remarkably, even upon disintegration, CD $169^{+}$SCS macrophage cell-derived blebs are able to bind to IL-17 lymphocytes and NK cells $(41,43)$. Apparently, CD169 acts as an adhesion receptor that facilitates the interaction of $\mathrm{CD} 69^{+}$macrophages with other innate immune cells.

Interestingly, in vivo blockade of CD169 receptor resulted in impaired MVA-specific, but not VSV-specific CD8 ${ }^{+} \mathrm{T}$ cell responses (44). This observation could be explained by the dispensability of the cross-presentation process during certain viral infections, such as VSV in which DCs are likely to be directly infected (94). Specifically, KLRG- $1^{\text {low }} \mathrm{CD} 8^{+} \mathrm{T}$ cells with memory potential were negatively affected upon CD169 blocking in MVAinfected animals, indicating that $\mathrm{CD} 169^{+}$macrophage-mediated antigen transfer to $\mathrm{CDC1}$ s might facilitate memory responses as well. In line with this, collaboration between splenic CD169+ macrophages and $\mathrm{CDC} 1 \mathrm{~s}$ was important for activation of memory $\mathrm{CD}^{+}{ }^{+} \mathrm{T}$ cell responses in VSV infection (33).

Van Dinther et al. showed that CLEC9A/DNGR-1 expressed on $\mathrm{cDC} 1$ enhanced $\mathrm{CD}^{+} \mathrm{T}$ cell cross-priming of antigens targeted to $\mathrm{CD} 169^{+}$macrophages (44). CLEC9A/DNGR-1 binds to F-actin exposed on dying cells and while it does not increase antigen transfer, it enhances $\mathrm{T}$ cell responses toward cellassociated material and in viral infections (110-112). A number of studies have indicated the disappearance or death of CD169 ${ }^{+}$ macrophages induced by viral infection or other inflammatory agents $(44,60,105)$. This suggests that upon infection, CD169+ macrophages quickly die and thereby form a cellular substrate for antigen transfer by the cross-presenting $\mathrm{cDC} 1$. This process could be of particular importance in viral infections, such as MVA, that solely depend on cross-presentation as opposed to VSV where the virus directly infects DCs (44).

\section{CD169 as a Viral Receptor That Mediates Virus Capture and Trans-infection}

A decade ago, CD169 expressed on monocyte-derived DCs was found to promote HIV infection. This discovery brought a paradigm shift in the HIV field with CD169 replacing DCSIGN as the main capture receptor responsible not only for HIV adhesion, but also for trans-infection (113-116). Following binding of CD169 to virus membrane-associated glycolipids (GM3), HIV-1 and CD169 were demonstrated to travel together to and accumulate at a non-lysosomal compartment. Consequently, the concentration of HIV-1 and CD169 at the so called infectious synapse enabled trans-infection of $\mathrm{CD} 4^{+} \mathrm{T}$ cells (117). A similar trans-infection process was also shown to be important for henipavirus infection (118).

In a study that focused on MLV and HIV infection in vivo, CD169-mediated virus capture was also reported to occur via CD169 binding to gangliosides on the viral membrane (93). Interestingly, $\mathrm{CD} 169^{+}$macrophages that had captured MLV, but were not infected themselves, were responsible for transinfection of permissive B cells which facilitated spread of the infection. Accordingly, considerably lower numbers of virusinfected cells were detected both in peripheral lymph nodes and spleen upon blocking of CD169 and in CD169-deficient mice. This clearly illustrated the importance of CD169 for effective virus dissemination. In line with this, MLV was also demonstrated to exploit CD169 expressed on primary mouse bone marrow macrophages for trans-infection of proliferating $B$ cells (95). Apart from aforementioned retroviral models, a study performed in a porcine reproductive and respiratory syndrome virus (PRRSV) also experimentally addressed the role of CD169 in virus anchoring (119). The authors proved that the attachment of the virus was dependent on the sialic acid binding activity of the receptor that binds to sialylated viral glycoproteins on PRRSV.

While substantial evidence from retroviral studies validates CD169 as a viral receptor that is exploited by the pathogen for its dissemination, numerous studies in viral models have demonstrated the importance of CD169 expressing macrophages for the containment of viral infection and localized production of antigen. The latter suggests that these macrophages form a reservoir of viral antigen for transfer to $\mathrm{cDC} 1$. A small number of studies suggest that a similar process may take place in certain bacterial infections.

\section{CD169+ Macrophages Efficiently Trap Bacteria and Allow Trans-infection of cDCs}

Similar to what has been shown in viral infections, several studies using the Listeria monocytogenes ( $\mathrm{Lm}$ ) model confirmed CD169+ macrophages as the initial cellular host that effectively traps the bacteria $(36,120-122)$. While as early as $2 \mathrm{~h}$ post-infection, the 
majority of Lm was detected within macrophages in the marginal zone, by $9 \mathrm{~h} \mathrm{CD} 11 \mathrm{c}^{+}$DCs were the main cell type carrying Lm (121). Two photon microscopy results showed clustering of Lm-specific $\mathrm{T}$ cells that associated with $\mathrm{CD}_{11 c^{+}} \mathrm{DCs}$ in periarteriolar lymphoid sheath (PALS), which was indicative of ongoing antigen presentation. At $24 \mathrm{~h} \mathrm{Lm}$-infection foci were mainly localized to PALS where Lm was shown to replicate extensively. Using a CD11c-DTR model that allows for CD11c depletion upon DT injection, the authors confirmed that Lm transport to the PALS and subsequent antigen presentation were dependent on the presence of cDCs. However, as mentioned already, CD11c-DTR model also abrogates CD11c- expressing CD $169^{+}$macrophages. Therefore, only subsequent experiments performed in the Batf $3^{-/-}$model, formally established the role of cross-presenting cDC1 in Lm delivery to the PALS $(120,122)$.

Recently, Perez et al. (122) also noted a shift in Lm distribution from $\mathrm{CD} 169^{+}$macrophages to $\mathrm{CDC} 1$ over the course of infection and showed that $\mathrm{CD} 169^{+}$macrophages mediate trans-infection of $\mathrm{cDC} 1$. Accordingly, while in wild type animals $\mathrm{CDC} 1$ formed clusters near $\mathrm{Lm}$-infected $\mathrm{CD} 169^{+}$macrophages in the marginal zone and efficiently delivered Lm to PALS, in CD169-DTR mice such clusters were not present and transport to PALS was impaired. Therefore, the presence of $\mathrm{CD} 169^{+}$macrophages closely interacting with $\mathrm{cDC1}$ promoted trans-infection and enabled subsequent Lm entry to the PALS.

Similar to viral infections, $\mathrm{CD} 169^{+}$macrophages also control the spread of bacteria. Perez and colleagues reported increased bacterial titers in the spleen and blood of CD169-DTR mice, suggesting that these macrophages impede Lm replication and prevent Lm dissemination (122). Finally, using a CD169-DTRBatf3 ${ }^{-/}$model, that allows for conditional depletion of $\mathrm{CD} 169^{+}$ macrophages in cDC1-deficient mice, it was demonstrated that rapid $\mathrm{Lm}$ capture and clearance secured by $\mathrm{CD} 169^{+}$ macrophages was instrumental for Lm control. Interestingly, the authors showed that cytosolic replication within $\mathrm{CD} 169^{+}$ macrophages due to phagosomal escape was necessary for recruitment of $\mathrm{cDC1}$.

While $\mathrm{cDC} 1 \mathrm{~s}$ have been identified as replication- permissive cellular hosts for Lm, a recent study demonstrated that $\mathrm{CD}_{169^{+}}$macrophages can have a similar role in pneumococcal septicaemia (123). Upon infecting $\mathrm{CD}_{169}{ }^{+}$macrophages, Streptococcus pneumoniae evaded phagosomal clearance, proliferated intracellularly and after causing cell lysis disseminated to the bloodstream. The authors concluded that intracellular replication within $\mathrm{CD}_{169^{+}}$macrophages is crucial for resulting pneumococcal septicaemia.

Collectively, the findings from studies in bacterial infections, albeit almost exclusively performed in the Lm model, illustrate the importance of $\mathrm{CD}_{169^{+}}$macrophages as the initial cellular host. By capturing the bacteria, $\mathrm{CD} 169^{+}$macrophages initially mediate pathogen clearance and prevent systemic spread of the infection. However, they also serve as a bacterial reservoir that actually promotes propagation of the bacteria into the bloodstream at a later stage in the case of Streptococcus pneumonia or enable trans-infection of cDC1 by Lm. In addition to these two bacterial infections, the CD169 molecule has been shown to function as a receptor for bacterial uptake of pathogens rich in sialylated polysaccharides, such as Neisseria meningitidis, Campylobacter jejuni, and Trypanosoma cruzi (124-126). It remains to be established whether CD169 ${ }^{+}$ macrophages function as a bacterial and/or antigen reservoir in these infections.

\section{Uptake and Transfer of Apoptotic Cellular Material by CD169+ Macrophages and the Implications for Tolerance and Cancer Immunity}

The distinction between self and non-self is essential for the proper function of the immune system. Next to their essential role in initiating immune responses specific for pathogens, $\mathrm{CD}_{169^{+}}$macrophages have also been shown to play a role in the induction of tolerance and anti-cancer immune responses.

\section{Role of CD169+ Macrophages in Tolerance}

Continuous and non-inflammatory removal of apoptotic cell material is essential for the maintenance of tolerance. Using a transfer model of apoptotic cells, cDC1 cells were specifically shown to take up and present these cell-associated antigens to $\mathrm{CD}^{+} \mathrm{T}$ cells $(16,18,19)$ and subsequently induce tolerance in the steady state (127). One of the first observations indicating a tolerogenic function for $\mathrm{CD} 169^{+}$macrophages was made by Miyake et al., who generated CD169-DTR mice in which all marginal zone macrophages were eliminated upon injection with DT (47). Upon injection of apoptotic cells loaded with a fragment of the myelin oligodendrocyte glycoprotein peptide (MOG peptide), an accumulation of apoptotic cell content was observed in the marginal zone in wild type mice, which prevented the development of EAE. Depletion of marginal zone macrophages via DT administration in CD169-DTR mice resulted in a failure of induction of tolerance and a switch in the uptake of apoptotic cells from $\mathrm{CD}^{+}{ }^{+} \mathrm{cDC} 1 \mathrm{~s}$ to $\mathrm{CD} 8^{-}{ }^{\mathrm{cDC}} 2 \mathrm{~s}$ (47).

Next to cDC2s, also red pulp macrophages, have been accounted for the defective uptake of apoptotic cells and the abrogation of tolerance in the absence of marginal zone macrophages. When marginal zone macrophages were depleted by means of clodronate liposomes, an accumulation of apoptotic cells was detected in $\mathrm{F} 4 / 80^{+}$macrophages. This was correlated with the production of inflammatory cytokines and loss of tolerance induction (128).

In subsequent studies by McGaha et al. the interaction between $\mathrm{CD} 169^{+}$macrophages and DCs was investigated. In their system, intravenous injection of apoptotic cells induced the expression of CCL22 on CD169 ${ }^{+}$macrophages, which resulted in a coordinated clustering of CCR4-expressing $\mathrm{CDC} 1 \mathrm{~s}$ and regulatory $\mathrm{T}$ cells within the white pulp. The induction of tolerance was dependent on both $\mathrm{CD} 169^{+}$macrophages and CCR4 (129). In contrast, another study reported that CCL22 is produced by the $\mathrm{cDC} 1 \mathrm{~s}$ upon injection with apoptotic cells, showing that the role of the cell type that produces CCL22 remains to be clarified (130). However, together these studies indicate that marginal zone $\mathrm{CD} 169^{+}$macrophages and $\mathrm{CDC} 1 \mathrm{~s}$ are essential in the induction of tolerance via the uptake of apoptotic cells and suggest a functional collaboration in this process. 


\section{Uptake of Tumor Cell Material and Exosomes by CD169+ Macrophages Stimulate Anti-cancer Immunity}

The previously discussed role of $\mathrm{CD}_{169^{+}}$macrophages in mediating the removal of dying cells from the circulation to induce tolerance suggests that a similar process could potentially be involved in anti-tumor immunity. In this sense, a number of factors have been proposed to shift the balance of tolerance toward immunity. Whether DCs induce immunity is a contextdependent process, influenced by environmentally provided stimuli, stage and type of cell death as well as the location where it takes place $(131,132)$. An example of this has been provided by Lorenzi and colleagues, who demonstrated enhanced intracellular persistence of antigenic particles in $\mathrm{CDC1}$ upon injection of tumor apoptotic cells in combination with IFNI. After exposure to IFN-I, cDC1 not only contributed to the induction of OT-I proliferation, but also exhibited an enhanced lifespan and expression of co-stimulatory molecules (133). Since $\mathrm{CD} 169^{+}$macrophages can produce high amounts of IFN-I, in combination with antigen this could provide the optimal stimulus for DCs to be able to cross-present cell-associated tumor antigens and to induce $\mathrm{T}$ cell activation.

However, the question remains whether $\mathrm{CD}_{169}{ }^{+}$ macrophages have the capacity to cross-present tumor antigens autonomously. One of the first studies exploiting subcutaneously-injected dead cells showed these cells being transported throughout the lymphatic system to the lymph nodes, where SCS macrophages cross-presented dead cellassociated antigens to $\mathrm{CD} 8^{+} \mathrm{T}$ cells. Mice that were lacking SCS macrophages at the moment of vaccination did not reject the tumors successfully (134). Interestingly, in this model the $\mathrm{CD} 169^{+}$macrophages, and not $\mathrm{CDC} 1$, were thought to directly cross-prime $\mathrm{CD}^{+} \mathrm{T}$ cells. This is reminiscent of the direct presentation of adenoviral antigens in the study of Bernhard et al., although the latter cannot be formally referred to as crosspresentation (107). Further studies are necessary to determine whether $\mathrm{CD} 169^{+}$macrophages can cross-prime $\mathrm{CD} 8^{+} \mathrm{T}$ cells independently or always require the collaboration with $\mathrm{cDC} 1 \mathrm{~s}$.

In a model in which apoptotic cells were injected in vivo and induced $\mathrm{CD} 4^{+} \mathrm{T}$ cell activation, again macrophages were shown to be the main cells involved in the uptake and in their absence or the absence of $\mathrm{cDC} 1$ the $\mathrm{CD} 4^{+} \mathrm{T}$ cell activation was significantly decreased (135). Of note, an exosomal pathway was indicated to play a role in the cell-associated antigen transfer of macrophages to DCs. Exosomes are produced by many cell types and consist of small membrane vesicles that contain proteins, lipids, and nucleic acids. These vesicles can mediate transfer of such encapsulated molecules and thereby facilitate communication between cells (136). Exosomes have been found to be efficiently taken up by CD169 ${ }^{+}$macrophages and $\mathrm{CDC} 1$ in the spleen (137). McLellan and colleagues demonstrated that exosomes can express high levels of $\alpha 2,3$-linked sialic acids and bind abundantly to CD169 ${ }^{+}$ macrophages in the spleen. Interestingly, CD169-deficient mice raised stronger $\mathrm{CD}^{+} \mathrm{T}$ cell responses toward antigen-pulsed exosomes than wild type mice (138). A similar suppressive role of $\mathrm{CD} 169^{+}$macrophages was observed in the $\mathrm{T}$ cell response toward tumor-derived apoptotic vesicles (139).
These studies suggest that $\mathrm{CD} 69^{+}$macrophages scavenge exosomes and thereby prevent their uptake by other cell types. Proof of that concept was provided by Pittet and colleagues in a mice model bearing genetically modified B16F10 melanoma tumors. The authors observed that tumor-derived exosomes drained to the lymph node and bound to $\mathrm{CD} 169^{+}$macrophages, which prevented the interaction with $\mathrm{B}$ cells that produce tumor promoting IgG. Elimination of $\mathrm{CD} 169^{+}$macrophages by clodronate liposomes or by DT injection in the CD169-DTR mice promoted tumor growth. In the same study, melanoma-derived material was found in macrophages residing in the cancer-free sentinel lymph node of human biopsies, hinting to the potential relevance of these findings for human cancer research (140).

Several groups have reported association of the presence of $\mathrm{CD} 169^{+}$macrophages in lymph nodes with good tumor prognosis in human. Ohnishi and colleagues showed a correlation between $\mathrm{CD}_{169^{+}}$macrophages and $\mathrm{CD}^{+} \mathrm{T}$ cell infiltration in colorectal cancer, improving overall survival rates. Furthermore, they observed co-localization of $\mathrm{CD}^{+} \mathrm{T}$ cells and $\mathrm{CD} 169^{+}$macrophages in regional lymph node section stainings (141). Similarly, more recent work from the same group demonstrated that the presence of $\mathrm{CD}_{169^{+}}$macrophages in the lymph nodes was also correlated to $\mathrm{CD}^{+} \mathrm{T}$ cell infiltration in malignant melanoma, endometrial carcinoma (where higher numbers of NK cells were also found), breast cancer and bladder cancer (142-145), all leading to a better prognosis and increased survival rates. Quite remarkably, in the study in malignant melanoma, IFN- $\alpha$ producing cells were detected around $\mathrm{CD} 169^{+}$macrophages in the lymph node sinus area. Based on their morphology and marker expression, the authors hypothesized that the source of IFN- $\alpha$, supporting the action of $\mathrm{CD} 169^{+}$macrophages, could be $\mathrm{CD} 68^{+}$macrophages and pDCs (142). Altogether, these studies present robust data illustrating the importance of $\mathrm{CD} 69^{+}$macrophages in lymph nodes in proficient anti-tumor responses, characterized by a consistent $\mathrm{CD}^{+} \mathrm{T}$ cell infiltration that benefits patient prognosis and survival. However, while $\mathrm{CD}_{169^{+}}$macrophages where shown to co-localize with $\mathrm{CD} 8^{+} \mathrm{T}$ cells, no direct evidence of antigen presentation by $\mathrm{CD} 169^{+}$macrophages was provided at a functional level. Therefore, there might be room for other more specialized immune cells, such as $\mathrm{CDC} 1$ to cooperate in the process of $\mathrm{T}$ cell priming.

\section{Vaccination Strategies That Target to CD169+ Macrophages}

The presence of $\mathrm{CD} 169^{+}$macrophages in lymph nodes draining different tumor types and their correlation with a better patient survival, their unique capacity to screen the lymphatic and blood circulation and, finally, their capacity to collaborate with DCs, all point to $\mathrm{CD} 169^{+}$macrophages as appealing targets for the design of anti-cancer vaccines. Until now, several vaccination strategies targeting $\mathrm{CD} 169^{+}$macrophages have been evaluated experimentally.

Due to their high specificity and the restricted expression pattern of CD169, monoclonal antibodies have been tested for antigen delivery to $\mathrm{CD} 169^{+}$macrophages. Upon anti-CD169specific antibody targeting of OVA, strong CTL responses were 


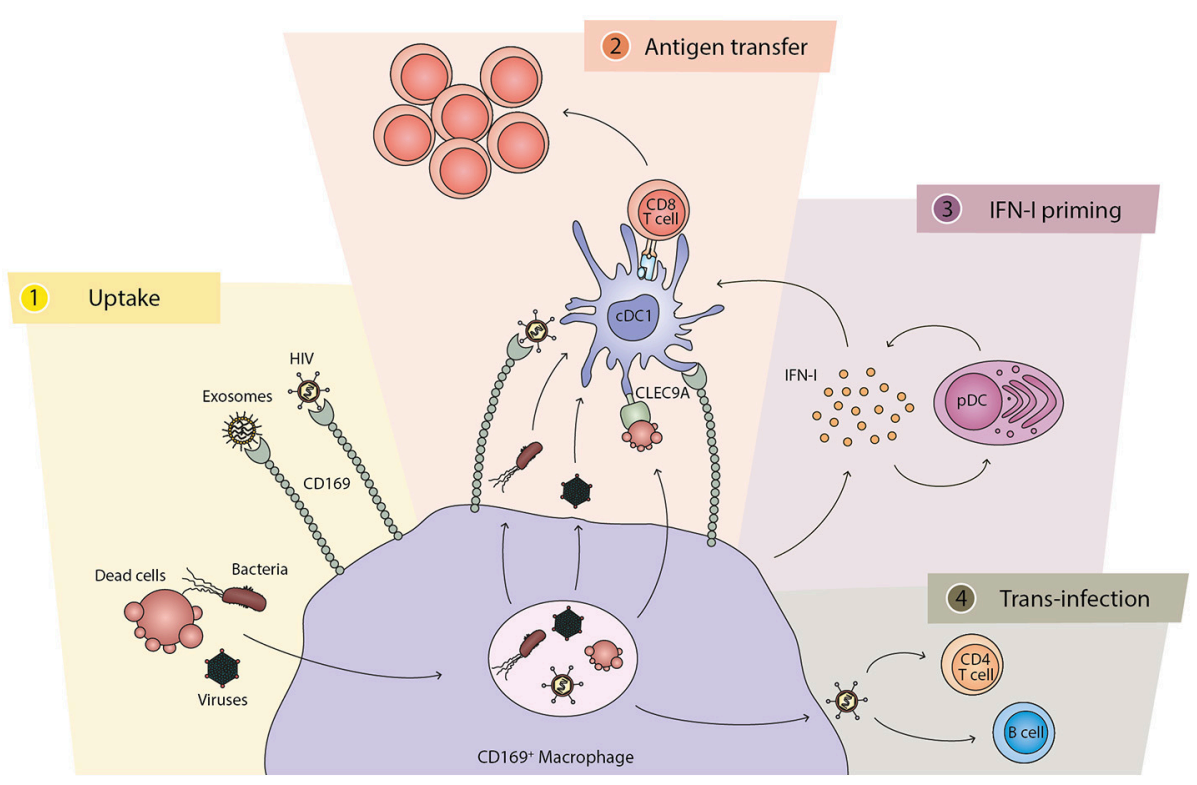

FIGURE 1 | The different functions of CD169+ macrophages and their cross-talk with cDC1. (1) Uptake: CD169+ macrophages capture and phagocytose pathogens, including bacteria and viruses, as well as dead cells. The CD169 molecule also directly binds to exosomes and specific pathogens, such as HIV. (2) Antigen transfer: CD169+ macrophages directly interact and present antigens to cDC1s for the generation of antigen-specific CD8 ${ }^{+} \mathrm{T}$ cell responses. While HIV particles are transferred via CD169, other components of bacteria and viruses can be transferred to cDC1s from the macrophages. Dead cells can stimulate cDC1s via CLEC9A expressed on the CDC1. The interaction between CD169+ macrophages and CDC1s is dependent on binding of CD169 to sialic acid structures on CDC1s. (3) IFN-I priming: after encounter with bacteria, dead cells, or viruses, CD169+ macrophages secrete IFN-I that is required for optimal activation of cDC1s and T cells. Subsequently, pDCs are recruited and their IFN-I production further amplifies the signal. (4) Trans-infection: in the case of HIV and MLV, CD169+ macrophages can also mediate viral trans-infection to CD4 T cells and B cells.

generated mediated by antigen transfer to $\mathrm{cDC1}$ (106). This effect was lost upon depletion of $\mathrm{CD} 169^{+}$macrophages by the administration of clodronate liposomes and was shown to be mediated by BATF3-dependent CDC1s (44). Antibody-mediated targeting of OVA to $\mathrm{CD} 169^{+}$macrophages also led to an isotypeswitched and high affinity antibody production due to germinal center activity. $\mathrm{CD} 169^{+}$macrophages retained intact antigen on their surface for days and upregulated costimulatory molecules for B cell interaction upon activation (103). This feature of $\mathrm{CD}_{169}{ }^{+}$macrophages to retain intact molecules on their membrane has been correlated with low expression of proteolytic enzymes (104).

On a different note, Delputte et al. demonstrated that monoclonal antibodies against CD169 were not only binding, but also being efficiently internalized in a clathrin-dependent manner. Immunotoxins or antigens could be delivered to $\mathrm{CD} 69^{+}$macrophages via antibody targeting, leading to killing of primary porcine macrophages and the generation of antiHSA humoral responses, respectively $(146,147)$. It is not clear why certain studies report internalization and others longterm presence on the cell surface with antibody targeting. Both processes could occur simultaneously, but these divergent results could also be due to antibodies binding to different regions of the CD169 molecule.

In addition, liposomes have been used to target antigens to $\mathrm{CD}_{169}{ }^{+}$macrophages. Chen and colleagues generated OVAcontaining liposomes decorated with $3^{\prime}$-BPCNeuAc, a synthetic ligand of CD169, and showed that targeting of IFN- $\alpha$ stimulated bone marrow-derived mouse macrophages with 3'-BPCNeuAcliposomes induced OVA specific $\mathrm{T}$ cell proliferation (148). Moreover, the same authors could also accomplish activation of iNKT cells by including the lipid antigen $\alpha$ GalCer in the $3^{\prime}$ BPCNeuAc-liposomes (149). CD169 ${ }^{+}$macrophages seem well equipped in stimulating NKT cells via CD1d, which subsequently help B cell responses $(42,150)$. Liposomes with the endogenous ligand for CD169, ganglioside GM3, have also been shown to bind to $\mathrm{CD}_{169^{+}}$monocyte-derived DCs (151). These studies indicate that also liposomal strategies could be employed to target antigens and activating agents to $\mathrm{CD} 169^{+}$macrophages.

\section{CONCLUDING REMARKS}

In recent years a considerable number of studies have focused on the role that $\mathrm{CD} 169^{+}$macrophages play in the SCS of the lymph node and the marginal zone of the spleen (summarized in Figure 1). These studies, as discussed in this review, point to $\mathrm{CD}_{169^{+}}$macrophages as the main cell type to capture viruses, bacteria, dead cells and exosomes from the lymph fluid and the blood. This filtering capacity prevents further dissemination and enables a localized contained production of antigen that is efficiently transferred to DCs and B cells for the activation of adaptive immune responses. The collaboration between $\mathrm{CD} 169^{+}$ macrophages and $\mathrm{CDC} 1 \mathrm{~s}$ is especially important in the activation of $\mathrm{CD}^{+} \mathrm{T}$ cell responses toward viral or tumor antigens. In this context, IFN-I derived from $\mathrm{CD} 169^{+}$macrophages and pDCs plays a crucial role for an appropriate $\mathrm{cDC1}$ activation. 
However, a number of pathogens have exploited this pathway and utilize $\mathrm{CD} 169^{+}$macrophages as a niche to replicate and to mediate trans-infection of other cell types. In the coming years, the role of the human equivalent of this cell type will hopefully be elucidated and the development of treatment strategies to boost or down-regulate immune responses via the actions of the $\mathrm{CD} 69^{+}$macrophages may well be expected.

\section{AUTHOR CONTRIBUTIONS}

All authors listed have made a substantial, direct and intellectual contribution to the work, and approved it for publication.

\section{REFERENCES}

1. Guilliams M, Ginhoux F, Jakubzick C, Naik SH, Onai N, Schraml BU, et al. Dendritic cells, monocytes and macrophages: a unified nomenclature based on ontogeny. Nat Rev Immunol. (2014) 14:571-8. doi: 10.1038/nri3712

2. Ginhoux F, Guilliams M. Tissue-resident macrophage ontogeny and homeostasis. Immunity (2016) 44:439-49. doi: 10.1016/j.immuni.2016.02.024

3. Lavin Y, Mortha A, Rahman A, Merad M. Regulation of macrophage development and function in peripheral tissues. Nat Rev Immunol. (2015) 15:731-44. doi: 10.1038/nri3920

4. Davies LC, Jenkins SJ, Allen JE, Taylor PR. Tissue-resident macrophages. Nat Immunol. (2013) 14:986-95. doi: 10.1038/ni.2705

5. Amit I, Winter DR, Jung $\mathrm{S}$. The role of the local environment and epigenetics in shaping macrophage identity and their effect on tissue homeostasis. Nat Immunol. (2016) 17:18-25. doi: 10.1038/ni.3325

6. Mowat AM, Scott CL, Bain CC. Barrier-tissue macrophages: functional adaptation to environmental challenges. Nat Med. (2017) 23:1258-70. doi: $10.1038 / \mathrm{nm} .4430$

7. Jakubzick CV, Randolph GJ, Henson PM. Monocyte differentiation and antigen-presenting functions. Nat Rev Immunol. (2017) 17:349-62. doi: $10.1038 /$ nri.2017.28

8. Satpathy AT, Wu X, Albring JC, Murphy KM. Re(de)fining the dendritic cell lineage. Nat Immunol. (2012) 13:1145-54. doi: 10.1038/ni.2467

9. Mildner A, Jung S. Development and function of dendritic cell subsets. Immunity (2014) 40:642-56. doi: 10.1016/j.immuni.2014.04.016

10. Beijer MR, Kraal G, den Haan JM. Vitamin A and dendritic cell differentiation. Immunology (2014) 142:39-45. doi: 10.1111/imm.12228

11. See P, Dutertre CA, Chen J, Gunther P, McGovern N, Irac SE, et al. Mapping the human DC lineage through the integration of high-dimensional techniques. Science (2017) 356:eaag3009. doi: 10.1126/science.aag3009

12. Villani AC, Satija R, Reynolds G, Sarkizova S, Shekhar K, Fletcher J, et al. Single-cell RNA-seq reveals new types of human blood dendritic cells, monocytes, and progenitors. Science (2017) 356:eaah4573. doi: 10.1126/science.aah4573

13. Alcantara-Hernandez M, Leylek R, Wagar LE, Engleman EG, Keler T, Marinkovich MP, et al. High-dimensional phenotypic mapping of human dendritic cells reveals interindividual variation and tissue specialization. Immunity (2017) 47:1037-50.e6. doi: 10.1016/j.immuni.2017.11.001

14. Bevan MJ. Cross-priming for a secondary cytotoxic response to minor $\mathrm{H}$ antigens with $\mathrm{H}-2$ congenic cells which do not cross-react in the cytotoxic assay. J Exp Med. (1976) 143:1283-8.

15. Cruz FM, Colbert JD, Merino E, Kriegsman BA, Rock KL. The biology and underlying mechanisms of cross-presentation of exogenous antigens on MHC-I molecules. Annu Rev Immunol. (2017) 35:149-76. doi: 10.1146/annurev-immunol-041015-0 55254

16. den Haan JM, Lehar SM, Bevan MJ. CD8(+) but not CD8(-) dendritic cells cross-prime cytotoxic T cells in vivo. J Exp Med. (2000) 192:1685-96. doi: $10.1084 /$ jem.192.12.1685

\section{FUNDING}

This work was supported by grants from the Dutch Cancer Society (VU2013-5940 and VU2016-10449) a grant from the VUmc CCA (grant 2015-5-22) to JdH and a EU research framework programme grant (H2020-MSCA-ITN-2014-ETN642870) to DC4U/MLV.

\section{ACKNOWLEDGMENTS}

The authors thank D. van Dinther for critical review of the manuscript.

17. Segura E, Amigorena S. Cross-Presentation in mouse and human dendritic cells. Adv Immunol. (2015) 127:1-31. doi: 10.1016/bs.ai.2015.03.002

18. Schulz O, Reise Sousa C. Cross-presentation of cell-associated antigens by CD8alpha ${ }^{+}$dendritic cells is attributable to their ability to internalize dead cells. Immunology (2002) 107:183-9. doi: 10.1046/j.1365-2567.2002. 01513. $\mathrm{x}$

19. Iyoda T, Shimoyama S, Liu K, Omatsu Y, Akiyama Y, Maeda Y, et al. The $\mathrm{CD}^{+}$dendritic cell subset selectively endocytoses dying cells in culture and in vivo. J Exp Med. (2002) 195:1289-302. doi: 10.1084/jem.20020161

20. den Haan JM, Bevan MJ. Constitutive versus activation-dependent crosspresentation of immune complexes by CD8(+) and CD8(-) dendritic cells in vivo. J Exp Med. (2002) 196:817-27. doi: 10.1084/jem.20020295

21. Segura E, Albiston AL, Wicks IP, Chai SY, Villadangos JA. Different crosspresentation pathways in steady-state and inflammatory dendritic cells. Proc Natl Acad Sci USA. (2009) 106:20377-81. doi: 10.1073/pnas.0910295106

22. Tang-Huau TL, Gueguen P, Goudot C, Durand M, Bohec M, Baulande $\mathrm{S}$, et al. Human in vivo-generated monocyte-derived dendritic cells and macrophages cross-present antigens through a vacuolar pathway. Nat Commun. (2018) 9:2570. doi: 10.1038/s41467-018-04985-0

23. Grotzke JE, Sengupta D, Lu Q, Cresswell P. The ongoing saga of the mechanism(s) of MHC class I-restricted cross-presentation. Curr Opin Immunol. (2017) 46:89-96. doi: 10.1016/j.coi.2017.03.015

24. Blander JM, Regulation of the cell biology of antigen cross-presentation. Annu Rev Immunol. (2018) 36:717-53. doi: 10.1146/annurev-immunol-041015-055523

25. Delamarre L, Pack M, Chang H, Mellman I, Trombetta ES. Differential lysosomal proteolysis in antigen-presenting cells determines antigen fate. Science (2005) 307:1630-4. doi: 10.1126/science.1108003

26. Alloatti A, Kotsias F, Magalhaes JG, Amigorena S. Dendritic cell maturation and cross-presentation: timing matters! Immunol Rev. (2016) 272:97-108. doi: 10.1111/imr.12432

27. den Haan JM, Martinez-Pomares L, Macrophage heterogeneity in lymphoid tissues. Semin Immunopathol. (2013) 35:541-52. doi: 10.1007/s00281-013-0378-4

28. Martinez-Pomares L, Gordon S. $\mathrm{CD}_{169^{+}}$macrophages at the crossroads of antigen presentation. Trends Immunol. (2012) 33:66-70. doi: 10.1016/j.it.2011.11.001

29. Moseman EA, Iannacone M, Bosurgi L, Tonti E, Chevrier N, Tumanov A, et al. B cell maintenance of subcapsular sinus macrophages protects against a fatal viral infection independent of adaptive immunity. Immunity (2012) 36:415-26. doi: 10.1016/j.immuni.2012.01.013

30. Xu HC, Huang J, Khairnar V, Duhan V, Pandyra AA, Grusdat M, et al. Deficiency of the B cell-activating factor receptor results in limited CD169+ macrophage function during viral infection. J Virol. (2015) 89:4748-59. doi: 10.1128/JVI.02976-14

31. Takahashi K, Umeda S, Shultz LD, Hayashi S, Nishikawa S. Effects of macrophage colony-stimulating factor (M-CSF) on the development, differentiation, and maturation of marginal metallophilic macrophages and marginal zone macrophages in the spleen of osteopetrosis (op) mutant mice lacking functional M-CSF activity. J Leukoc Biol. (1994) 55:581-8. 
32. Shinde PV, Xu HC, Maney SK, Kloetgen A, Namineni S, Zhuang Y, et al. Tumor necrosis factor-mediated survival of CD169(+) cells promotes immune activation during vesicular stomatitis virus infection. J Virol. (2018) 92:e1637-17. doi: 10.1128/JVI.01637-17

33. Habbeddine M, Verthuy C, Rastoin O, Chasson L, Bebien M, Bajenoff M, et al. Receptor activator of NF-kappaB orchestrates activation of antiviral memory CD8 T cells in the spleen marginal zone. Cell Rep. (2017) 21:251527. doi: 10.1016/j.celrep.2017.10.111

34. A-Gonzalez N, Guillen JA, Gallardo G, Diaz M, de la Rosa JV, Hernandez IH, et al. The nuclear receptor LXRalpha controls the functional specialization of splenic macrophages. Nat Immunol. (2013) 14:831-9. doi: 10.1038/ ni. 2622

35. Seiler P, Aichele P, Odermatt B, Hengartner H, Zinkernagel RM, Schwendener RA. Crucial role of marginal zone macrophages and marginal zone metallophils in the clearance of lymphocytic choriomeningitis virus infection. Eur J Immunol. (1997) 27:2626-33. doi: 10.1002/eji.1830271023

36. Aichele P, Zinke J, Grode L, Schwendener RA, Kaufmann SH, Seiler P. Macrophages of the splenic marginal zone are essential for trapping of blood-borne particulate antigen but dispensable for induction of specific T cell responses. J Immunol. (2003) 171:1148-55. doi: 10.4049/jimmunol.171.3.1148

37. Junt T, Moseman EA, Iannacone M, Massberg S, Lang PA, Boes M, et al. Subcapsular sinus macrophages in lymph nodes clear lymph-borne viruses and present them to antiviral B cells. Nature (2007) 450:110-4. doi: $10.1038 /$ nature06287

38. Iannacone $\mathrm{M}$, Moseman EA, Tonti E, Bosurgi L, Junt T, Henrickson SE, et al. Subcapsular sinus macrophages prevent CNS invasion on peripheral infection with a neurotropic virus. Nature (2010) 465:1079-83. doi: 10.1038/nature09118

39. Gupta P, Lai SM, Sheng J, Tetlak P, Balachander A, Claser C, et al. Tissue-resident CD169(+) macrophages form a crucial front line against plasmodium infection. Cell Rep. (2016) 16:1749-61. doi: 10.1016/j.celrep.2016.07.010

40. Kastenmuller W, Torabi-Parizi P, Subramanian N, Lammermann T, Germain RN. A spatially-organized multicellular innate immune response in lymph nodes limits systemic pathogen spread. Cell (2012) 150:1235-48. doi: 10.1016/j.cell.2012.07.021

41. Zhang Y, Roth TL, Gray EE, Chen H, Rodda LB, Liang Y, et al. Migratory and adhesive cues controlling innate-like lymphocyte surveillance of the pathogen-exposed surface of the lymph node. Elife (2016) 5:e18156. doi: 10.7554/eLife.18156

42. Barral P, Polzella P, Bruckbauer A, van Rooijen N, Besra GS, Cerundolo $\mathrm{V}$, et al. CD169(+) macrophages present lipid antigens to mediate early activation of iNKT cells in lymph nodes. Nat Immunol. (2010) 11:303-12. doi: $10.1038 /$ ni. 1853

43. Gray EE, Friend S, Suzuki K, Phan TG, Cyster JG. Subcapsular sinus macrophage fragmentation and $\mathrm{CD}_{169^{+}}$bleb acquisition by closely associated IL-17-committed innate-like lymphocytes. PLoS ONE (2012) 7:e38258. doi: 10.1371/journal.pone.0038258

44. van Dinther D, Veninga H, Iborra S, Borg EGF, Hoogterp L, Olesek $\mathrm{K}$, et al. Functional CD169 on macrophages mediates interaction with dendritic cells for CD8(+) T cell cross-priming. Cell Rep. (2018) 22:1484-95. doi: 10.1016/j.celrep.2018.01.021

45. Van Rooijen N, Sanders A. Liposome mediated depletion of macrophages: mechanism of action, preparation of liposomes and applications. J Immunol Methods (1994) 174:83-93.

46. Kuka M, Iannacone M. The role of lymph node sinus macrophages in host defense. Ann N Y Acad Sci. (2014) 1319:38-46. doi: 10.1111/nyas.12387

47. Miyake Y, Asano K, Kaise H, Uemura M, Nakayama M, Tanaka M. Critical role of macrophages in the marginal zone in the suppression of immune responses to apoptotic cell-associated antigens. J Clin Invest. (2007) 117:2268-78. doi: 10.1172/JCI31990

48. Jung S, Unutmaz D, Wong P, Sano G, De los Santos K, Sparwasser T, et al. In vivo depletion of $\mathrm{CD}_{11 \mathrm{c}^{+}}$dendritic cells abrogates priming of $\mathrm{CD} 8^{+}$ $\mathrm{T}$ cells by exogenous cell-associated antigens. Immunity (2002) 17:211-20. doi: 10.1016/S1074-7613(02)00365-5

49. Probst HC, Tschannen K, Odermatt B, Schwendener R, Zinkernagel RM, Van Den Broek M. Histological analysis of CD11c-DTR/GFP mice after in vivo depletion of dendritic cells. Clin Exp Immunol. (2005) 141:398-404 doi: 10.1111/j.1365-2249.2005.02868.x

50. Karasawa K, Asano K, Moriyama S, Ushiki M, Monya M, Iida M, et al. Vascular-resident CD169-positive monocytes and macrophages control neutrophil accumulation in the kidney with ischemia-reperfusion injury. $J$ Am Soc Nephrol. (2015) 26:896-906. doi: 10.1681/ASN.2014020195

51. Ivashkiv LB, Donlin LT. Regulation of type I interferon responses. Nat Rev Immunol. (2014) 14:36-49. doi: 10.1038/nri3581

52. Yan N, Chen ZJ. Intrinsic antiviral immunity. Nat Immunol. (2012) 13:21422. doi: $10.1038 /$ ni.2229

53. Kovarik P, Castiglia V, Ivin M, Ebner F. Type I interferons in bacterial infections, a balancing act. Front Immunol. (2016) 7:652. doi: 10.3389/fimmu.2016.00652

54. McNab F, Mayer-Barber K, Sher A, Wack A, O'Garra A. Type I interferons in infectious disease. Nat Rev Immunol. (2015) 15:87-103. doi: 10.1038/nri3787

55. Farrell HE, Bruce K, Lawler C, Cardin RD, Davis-Poynter NJ, Stevenson PG. Type 1 interferons and NK cells limit murine cytomegalovirus escape from the lymph node subcapsular sinus. PLoS Pathog. (2016) 12:e1006069. doi: 10.1371/journal.ppat.1006069

56. Eloranta ML, Alm GV. Splenic marginal metallophilic macrophages and marginal zone macrophages are the major interferon-alpha/beta producers in mice upon intravenous challenge with herpes simplex virus. Scand J Immunol. (1999) 49:391-4.

57. Lawler C, Tan CS, Simas JP, Stevenson PG. Type I interferons and NK cells restrict gammaherpesvirus lymph node infection. J Virol. (2016) 90:9046-57. doi: 10.1128/JVI.01108-16

58. Shaabani N, Duhan V, Khairnar V, Gassa A, Ferrer-Tur R, Haussinger D, et al. CD169(+) macrophages regulate PD-L1 expression via type I interferon and thereby prevent severe immunopathology after LCMV infection. Cell Death Dis. (2016) 7:e2446. doi: 10.1038/cddis.2016.350

59. Garcia Z, Lemaitre F, van Rooijen N, Albert ML, Levy Y, Schwartz O, et al. Subcapsular sinus macrophages promote NK cell accumulation and activation in response to lymph-borne viral particles. Blood (2012) 120:474450. doi: 10.1182/blood-2012-02-408179

60. Sagoo P, Garcia Z, Breart B, Lemaitre F, Michonneau D, Albert ML, et al. In vivo imaging of inflammasome activation reveals a subcapsular macrophage burst response that mobilizes innate and adaptive immunity. Nat Med. (2016) 22:64-71. doi: 10.1038/nm.4016

61. Swiecki M, Colonna M. The multifaceted biology of plasmacytoid dendritic cells. Nat Rev Immunol. (2015) 15:471-85. doi: 10.1038/nri3865

62. Brewitz A, Eickhoff S, Dahling S, Quast T, Bedoui S, Kroczek RA, et al. CD8(+) T Cells orchestrate pDC-XCR1(+) dendritic cell spatial and functional cooperativity to optimize priming. Immunity (2017) 46:205-19. doi: 10.1016/j.immuni.2017.01.003

63. Spaulding E, Fooksman D, Moore JM, Saidi A, Feintuch CM, Reizis B, et al. STING-licensed macrophages prime type I IFN production by plasmacytoid dendritic cells in the bone marrow during severe plasmodium yoelii malaria. PLoS Pathog. (2016) 12:e1005975. doi: 10.1371/journal.ppat.1005975

64. Swiecki M, Gilfillan S, Vermi W, Wang Y, Colonna M. Plasmacytoid dendritic cell ablation impacts early interferon responses and antiviral $\mathrm{NK}$ and CD8(+) $\mathrm{T}$ cell accrual. Immunity (2010) 33:955-66. doi: 10.1016/j.immuni.2010.11.020

65. Fitzgerald-Bocarsly P, Feng D. The role of type I interferon production by dendritic cells in host defense. Biochimie (2007) 89:843-55. doi: 10.1016/j.biochi.2007.04.018

66. Simmons DP, Wearsch PA, Canaday DH, Meyerson HJ, Liu YC, Wang Y, et al. Type I IFN drives a distinctive dendritic cell maturation phenotype that allows continued class II MHC synthesis and antigen processing. J Immunol. (2012) 188:3116-26. doi: 10.4049/jimmunol.1101313

67. Asselin-Paturel C, Brizard G, Chemin K, Boonstra A, O'Garra A, Vicari A, et al. Type I interferon dependence of plasmacytoid dendritic cell activation and migration. J Exp Med. (2005) 201:1157-67. doi: 10.1084/jem.20041930

68. Kreutz M, Bakdash G, Dolen Y, Skold AE, van Hout-Kuijer MA, de Vries IJ, et al. Type I IFN-mediated synergistic activation of mouse and human DC subsets by TLR agonists. Eur J Immunol. (2015) 45:2798-809. doi: 10.1002/eji.201545583

69. Spadaro F, Lapenta C, Donati S, Abalsamo L, Barnaba V, Belardelli F, et al. IFN-alpha enhances cross-presentation in human dendritic cells by 
modulating antigen survival, endocytic routing, and processing. Blood (2012) 119:1407-17. doi: 10.1182/blood-2011-06-363564

70. Le Bon A, Etchart N, Rossmann C, Ashton M, Hou S, Gewert D, et al. Crosspriming of $\mathrm{CD}^{+} \mathrm{T}$ cells stimulated by virus-induced type I interferon. Nat Immunol. (2003) 4:1009-15. doi: 10.1038/ni978

71. Diamond MS, Kinder M, Matsushita H, Mashayekhi M, Dunn GP, Archambault JM, et al. Type I interferon is selectively required by dendritic cells for immune rejection of tumors. J Exp Med. (2011) 208:1989-2003. doi: 10.1084/jem.20101158

72. Fuertes MB, Kacha AK, Kline J, Woo SR, Kranz DM, Murphy KM, et al. Host type I IFN signals are required for antitumor $\mathrm{CD}^{+} \mathrm{T}$ cell responses through CD8\{alpha\} ${ }^{+}$dendritic cells. J Exp Med. (2011) 208:2005-16. doi: $10.1084 /$ jem.20101159

73. Dalod M, Hamilton T, Salomon R, Salazar-Mather TP, Henry SC, Hamilton JD, et al. Dendritic cell responses to early murine cytomegalovirus infection: subset functional specialization and differential regulation by interferon alpha/beta. J Exp Med. (2003) 197:885-98. doi: 10.1084/jem.20021522

74. Schulz O, Diebold SS, Chen M, Naslund TI, Nolte MA, Alexopoulou L, et al. Toll-like receptor 3 promotes cross-priming to virus-infected cells. Nature (2005) 433:887-92. doi: 10.1038/nature03326

75. Wei J, Waithman J, Lata R, Mifsud NA, Cebon J, Kay T, et al. Influenza A infection enhances cross-priming of $\mathrm{CD}^{+} \mathrm{T}$ cells to cell-associated antigens in a TLR7- and type I IFN-dependent fashion. J Immunol. (2010) 185:6013-22. doi: 10.4049/jimmunol.1002129

76. Shimizu K, Asakura M, Shinga J, Sato Y, Kitahara S, Hoshino K, et al. Invariant NKT cells induce plasmacytoid dendritic cell (DC) cross-talk with conventional DCs for efficient memory $\mathrm{CD} 8^{+} \mathrm{T}$ cell induction. J Immunol. (2013) 190:5609-19. doi: 10.4049/jimmunol.1300033

77. Rajagopal D, Paturel C, Morel Y, Uematsu S, Akira S, Diebold SS. Plasmacytoid dendritic cell-derived type I interferon is crucial for the adjuvant activity of Toll-like receptor 7 agonists. Blood (2010) 115:1949-57. doi: 10.1182/blood-2009-08-238543

78. Webb LM, Lundie RJ, Borger JG, Brown SL, Connor LM, Cartwright AN, et al. Type I interferon is required for T helper (Th) 2 induction by dendritic cells. EMBO J. (2017) 36:2404-18. doi: 10.15252/embj.201695345

79. Longhi MP, Trumpfheller C, Idoyaga J, Caskey M, Matos I, Kluger C, et al. Dendritic cells require a systemic type I interferon response to mature and induce CD $4^{+}$Th1 immunity with poly IC as adjuvant. J Exp Med. (2009) 206:1589-602. doi: 10.1084/jem.20090247

80. Le Bon A, Schiavoni G, D'Agostino G, Gresser I, Belardelli F, Tough DF. Type I interferons potently enhance humoral immunity and can promote isotype switching by stimulating dendritic cells in vivo. Immunity. (2001) 14:461-70. doi: 10.1016/S1074-7613(01)00126-1

81. Cucak H, Yrlid U, Reizis B, Kalinke U, Johansson-Lindbom B. Type I interferon signaling in dendritic cells stimulates the development of lymph-node-resident T follicular helper cells. Immunity. (2009) 31:491-501. doi: 10.1016/j.immuni.2009.07.005

82. Lapenta C, Santini SM, Spada M, Donati S, Urbani F, Accapezzato D, et al. IFN-alpha-conditioned dendritic cells are highly efficient in inducing crosspriming CD8(+) T cells against exogenous viral antigens. Eur J Immunol. (2006) 36:2046-60. doi: 10.1002/eji.200535579

83. Lattanzi L, Rozera C, Marescotti D, D’Agostino G, Santodonato L, Cellini S, et al. IFN-alpha boosts epitope cross-presentation by dendritic cells via modulation of proteasome activity. Immunobiology (2011) 216:537-47. doi: 10.1016/j.imbio.2010.10.003

84. Higgs BW, Liu Z, White B, Zhu W, White WI, Morehouse C, et al. Patients with systemic lupus erythematosus, myositis, rheumatoid arthritis and scleroderma share activation of a common type I interferon pathway. Ann Rheum Dis. (2011) 70:2029-36. doi: 10.1136/ard.2011.1 50326

85. Blanco P, Palucka AK, Gill M, Pascual V, Banchereau J. Induction of dendritic cell differentiation by IFN-alpha in systemic lupus erythematosus. Science (2001) 294:1540-3. doi: 10.1126/science.10 64890

86. Nestle FO, Conrad C, Tun-Kyi A, Homey B, Gombert M, Boyman O, et al. Plasmacytoid predendritic cells initiate psoriasis through interferon-alpha production. J Exp Med. (2005) 202:135-43. doi: 10.1084/jem.20050500
87. York MR, Nagai T, Mangini AJ, Lemaire R, van Seventer JM, Lafyatis R. A macrophage marker, Siglec-1, is increased on circulating monocytes in patients with systemic sclerosis and induced by type I interferons and toll-like receptor agonists. Arthritis Rheum. (2007) 56:1010-20. doi: 10.1002/art.22382

88. Bogie JF, Boelen E, Louagie E, Delputte P, Elewaut D, van Horssen J, et al. CD169 is a marker for highly pathogenic phagocytes in multiple sclerosis. Mult Scler. (2018) 24:290-300. doi: 10.1177/1352458517698759

89. Zinselmeyer BH, Heydari S, Sacristan C, Nayak D, Cammer M, Herz J, et al. PD-1 promotes immune exhaustion by inducing antiviral $\mathrm{T}$ cell motility paralysis. J Exp Med. (2013) 210:757-74. doi: 10.1084/jem.20121416

90. Honke N, Shaabani N, Merches K, Gassa A, Kraft A, Ehrhardt K, et al. Immunoactivation induced by chronic viral infection inhibits viral replication and drives immunosuppression through sustained IFN-I responses. Eur J Immunol. (2016) 46:372-80. doi: 10.1002/eji.201545765

91. Schwandt T, Schumak B, Gielen GH, Jungerkes F, Schmidbauer P, Klocke K, et al. Expression of type I interferon by splenic macrophages suppresses adaptive immunity during sepsis. EMBO J. (2012) 31:201-13. doi: 10.1038/emboj.2011.380

92. Hickman HD, Takeda K, Skon CN, Murray FR, Hensley SE, Loomis J, et al. Direct priming of antiviral $\mathrm{CD} 8^{+} \mathrm{T}$ cells in the peripheral interfollicular region of lymph nodes. Nat Immunol. (2008) 9:155-65. doi: 10.1038/ni1557

93. Sewald X, Ladinsky MS, Uchil PD, Beloor J, Pi R, Herrmann C, et al. Retroviruses use CD169-mediated trans-infection of permissive lymphocytes to establish infection. Science (2015) 350:563-7. doi: 10.1126/science.aab2749

94. Honke N, Shaabani N, Cadeddu G, Sorg UR, Zhang DE, Trilling M, et al. Enforced viral replication activates adaptive immunity and is essential for the control of a cytopathic virus. Nat Immunol. (2011) 13:51-7. doi: $10.1038 /$ ni.2169

95. Erikson E, Wratil PR, Frank M, Ambiel I, Pahnke K, Pino M, et al. Mouse siglec-1 mediates trans-infection of surface-bound murine leukemia virus in a sialic acid n-acyl side chain-dependent manner. J Biol Chem. (2015) 290:27345-59. doi: 10.1074/jbc.M115.681338

96. Akiyama H, Ramirez NP, Gibson G, Kline C, Watkins S, Ambrose Z, et al. Interferon-inducible CD169/siglec1 attenuates anti-HIV-1 effects of alpha interferon. J Virol. (2017) 91:e00972-17. doi: 10.1128/JVI.00972-17

97. Winkelmann ER, Widman DG, Xia J, Johnson AJ, van Rooijen N, Mason PW, et al. Subcapsular sinus macrophages limit dissemination of West Nile virus particles after inoculation but are not essential for the development of West Nile virus-specific T cell responses. Virology (2014) 450-51:278-89. doi: 10.1016/j.virol.2013.12.021

98. Frederico B, Chao B, Lawler C, May JS, Stevenson PG. Subcapsular sinus macrophages limit acute gammaherpesvirus dissemination. J Gen Virol. (2015) 96:2314-27. doi: 10.1099/vir.0.000140

99. Farrell HE, Davis-Poynter N, Bruce K, Lawler C, Dolken L, Mach M, et al. Lymph node macrophages restrict murine cytomegalovirus dissemination. $J$ Virol. (2015) 89:7147-58. doi: 10.1128/JVI.00480-15

100. Duhan V, Khairnar V, Friedrich SK, Zhou F, Gassa A, Honke N, et al. Virus-specific antibodies allow viral replication in the marginal zone, thereby promoting CD8(+) T-cell priming and viral control. Sci Rep. (2016) 6:19191. doi: 10.1038/srep19191

101. Carrasco YR, Batista FD. B cells acquire particulate antigen in a macrophage-rich area at the boundary between the follicle and the subcapsular sinus of the lymph node. Immunity (2007) 27:160-71. doi: 10.1016/j.immuni.2007.06.007

102. Phan TG, Grigorova I, Okada T, Cyster JG. Subcapsular encounter and complement-dependent transport of immune complexes by lymph node B cells. Nat Immunol. (2007) 8:992-1000. doi: 10.1038/ni1494

103. Veninga H, Borg EG, Vreeman K, Taylor PR, Kalay H, van Kooyk Y, et al. Antigen targeting reveals splenic $\mathrm{CD} 169^{+}$macrophages as promoters of germinal center B-cell responses. Eur J Immunol. (2015) 45:747-57. doi: 10.1002/eji.201444983

104. Phan TG, Green JA, Gray EE, Xu Y, Cyster JG. Immune complex relay by subcapsular sinus macrophages and noncognate B cells drives antibody affinity maturation. Nat Immunol. (2009) 10:786-93. doi: 10.1038/ni.1745

105. Gaya M, Castello A, Montaner B, Rogers N, Reis e Sousa C, Bruckbauer A, Batista FD. Host response. Inflammation-induced disruption of SCS 
macrophages impairs B cell responses to secondary infection. Science (2015) 347:667-72. doi: 10.1126/science.aaa1300

106. Backer R, Schwandt T, Greuter M, Oosting M, Jungerkes F, Tuting T, et al. Effective collaboration between marginal metallophilic macrophages and $\mathrm{CD}^{+}$dendritic cells in the generation of cytotoxic T cells. Proc Natl Acad Sci USA. (2010) 107:216-21. doi: 10.1073/pnas.0909541107

107. Bernhard CA, Ried C, Kochanek S, Brocker T. CD $169^{+}$macrophages are sufficient for priming of CTLs with specificities left out by crosspriming dendritic cells. Proc Natl Acad Sci USA. (2015) 112:5461-6. doi: $10.1073 /$ pnas. 1423356112

108. Crocker PR, Freeman S, Gordon S, Kelm S. Sialoadhesin binds preferentially to cells of the granulocytic lineage. J Clin Invest. (1995) 95:635-43. doi: 10.1172/JCI117708

109. van den Berg TK, Breve JJ, Damoiseaux JG, Dopp EA, Kelm S, Crocker PR, et al. Sialoadhesin on macrophages: its identification as a lymphocyte adhesion molecule. J Exp Med. (1992) 176:647-55.

110. Sancho D, Joffre OP, Keller AM, Rogers NC, Martinez D, Hernanz-Falcon P, et al. Identification of a dendritic cell receptor that couples sensing of necrosis to immunity. Nature (2009) 458:899-903. doi: 10.1038/nature07750

111. Iborra S, Izquierdo HM, Martinez-Lopez M, Blanco-Menendez N, Reis e Sousa C, Sancho D. The DC receptor DNGR-1 mediates cross-priming of CTLs during vaccinia virus infection in mice. J Clin Invest. (2012) 122:162843. doi: $10.1172 /$ JCI60660

112. Ahrens S, Zelenay S, Sancho D, Hanc P, Kjaer S, Feest C, et al. Factin is an evolutionarily conserved damage-associated molecular pattern recognized by DNGR-1, a receptor for dead cells. Immunity (2012) 36:63545. doi: 10.1016/j.immuni.2012.03.008

113. Rempel H, Calosing C, Sun B, Pulliam L. Sialoadhesin expressed on IFNinduced monocytes binds HIV-1 and enhances infectivity. PLoS ONE (2008) 3:e1967. doi: 10.1371/journal.pone.0001967

114. Zou Z, Chastain A, Moir S, Ford J, Trandem K, Martinelli E, et al. Siglecs facilitate HIV-1 infection of macrophages through adhesion with viral sialic acids. PLoS ONE (2011) 6:e24559. doi: 10.1371/journal.pone.0024559

115. Izquierdo-Useros N, Lorizate M, Puertas MC, Rodriguez-Plata MT, Zangger N, Erikson E, et al. Siglec-1 is a novel dendritic cell receptor that mediates HIV-1 trans-infection through recognition of viral membrane gangliosides. PLoS Biol. (2012) 10:e1001448. doi: 10.1371/journal.pbio.1001448

116. Puryear WB, Yu X, Ramirez NP, Reinhard BM, Gummuluru S. HIV-1 incorporation of host-cell-derived glycosphingolipid GM3 allows for capture by mature dendritic cells. Proc Natl Acad Sci USA. (2012) 109:7475-80. doi: $10.1073 /$ pnas. 1201104109

117. Akiyama H, Ramirez NG, Gudheti MV, Gummuluru S. CD169-mediated trafficking of HIV to plasma membrane invaginations in dendritic cells attenuates efficacy of anti-gp120 broadly neutralizing antibodies. PLoS Pathog. (2015) 11:e1004751. doi: 10.1371/journal.ppat.1004751

118. Akiyama H, Miller C, Patel HV, Hatch SC, Archer J, Ramirez NG, et al. Virus particle release from glycosphingolipid-enriched microdomains is essential for dendritic cell-mediated capture and transfer of HIV-1 and henipavirus. $J$ Virol. (2014) 88:8813-25. doi: 10.1128/JVI.00992-14

119. Delputte PL, Van Breedam W, Delrue I, Oetke C, Crocker PR, Nauwynck HJ. Porcine arterivirus attachment to the macrophage-specific receptor sialoadhesin is dependent on the sialic acid-binding activity of the $\mathrm{N}$ terminal immunoglobulin domain of sialoadhesin. J Virol. (2007) 81:954650. doi: 10.1128/JVI.00569-07

120. Edelson BT, Bradstreet TR, Hildner K, Carrero JA, Frederick KE, Kc W, et al. CD8alpha $(+)$ dendritic cells are an obligate cellular entry point for productive infection by Listeria monocytogenes. Immunity (2011) 35:23648. doi: 10.1016/j.immuni.2011.06.012

121. Aoshi T, Carrero JA, Konjufca V, Koide Y, Unanue ER, Miller MJ. The cellular niche of Listeria monocytogenes infection changes rapidly in the spleen. Eur J Immunol. (2009) 39:417-25. doi: 10.1002/eji.200838718

122. Perez OA, Yeung ST, Vera-Licona P, Romagnoli PA, Samji T, Ural BB, et al. CD169(+) macrophages orchestrate innate immune responses by regulating bacterial localization in the spleen. Sci Immunol. (2017) 2:eaah5520. doi: 10.1126/sciimmunol.aah5520

123. Ercoli G, Fernandes VE, Chung WY, Wanford JJ, Thomson S, Bayliss CD, et al. Intracellular replication of Streptococcus pneumoniae inside splenic macrophages serves as a reservoir for septicaemia. Nat Microbiol. (2018) 3:600-610. doi: 10.1038/s41564-018-0147-1

124. Heikema AP, Koning RI, Duarte dos Santos Rico S, Rempel H, Jacobs BC, Endtz HP, et al. Enhanced, sialoadhesin-dependent uptake of Guillain-Barre syndrome-associated Campylobacter jejuni strains by human macrophages. Infect Immun. (2013) 81:2095-103. doi: 10.1128/IAI.01437-12

125. Jones C, Virji M, Crocker PR. Recognition of sialylated meningococcal lipopolysaccharide by siglecs expressed on myeloid cells leads to enhanced bacterial uptake. Mol Microbiol. (2003) 49:1213-25. doi: 10.1046/j.1365-2958.2003.03634.x

126. Monteiro VG, Lobato CS, Silva AR, Medina DV, de Oliveira MA Seabra SH, et al. Increased association of Trypanosoma cruzi with sialoadhesin positive mice macrophages. Parasitol Res. (2005) 97:380-5. doi: 10.1007/s00436-005-1460-1

127. Liu K, Iyoda T, Saternus M, Kimura Y, Inaba K, Steinman RM. Immune tolerance after delivery of dying cells to dendritic cells in situ. J Exp Med. (2002) 196:1091-7. doi: 10.1084/jem.20021215

128. McGaha TL, Chen Y, Ravishankar B, van Rooijen N, Karlsson, MCI. Marginal zone macrophages suppress innate and adaptive immunity to apoptotic cells in the spleen. Blood (2011) 117:5403-12. doi: 10.1182/blood-2010-11-320028

129. Ravishankar B, Shinde R, Liu H, Chaudhary K, Bradley J, Lemos HP, et al. Marginal zone $\mathrm{CD}_{169^{+}}$macrophages coordinate apoptotic cell-driven cellular recruitment and tolerance. Proc Natl Acad Sci USA. (2014) 111:421520. doi: 10.1073/pnas.1320924111

130. Hao S, Han X, Wang D, Yang Y, Li Q, Li X, et al. Critical role of CCL22/CCR4 axis in the maintenance of immune homeostasis during apoptotic cell clearance by splenic CD8alpha(+) CD103(+) dendritic cells. Immunology (2016) 148:174-86. doi: 10.1111/imm.12596

131. Griffith TS, Ferguson TA. Cell death in the maintenance and abrogation of tolerance: the five Ws of dying cells. Immunity (2011) 35:456-66. doi: 10.1016/j.immuni.2011.08.011

132. Garg AD, Agostinis P. Cell death and immunity in cancer: from danger signals to mimicry of pathogen defense responses. Immunol Rev. (2017) 280:126-48. doi: 10.1111/imr.12574

133. Lorenzi S, Mattei F, Sistigu A, Bracci L, Spadaro F, Sanchez M, et al. Type I IFNs control antigen retention and survival of CD8alpha $(+)$ dendritic cells after uptake of tumor apoptotic cells leading to cross-priming. J Immunol. (2011) 186:5142-50. doi: 10.4049/jimmunol.1004163

134. Asano K, Nabeyama A, Miyake Y, Qiu CH, Kurita A, Tomura M, et al. CD169-positive macrophages dominate antitumor immunity by crosspresenting dead cell-associated antigens. Immunity (2011) 34:85-95. doi: 10.1016/j.immuni.2010.12.011

135. Xu Y, Liu Y, Yang C, Kang L, Wang M, Hu J, et al. Macrophages transfer antigens to dendritic cells by releasing exosomes containing deadcell-associated antigens partially through a ceramide-dependent pathway to enhance CD4(+) T-cell responses. Immunology (2016) 149:157-71. doi: $10.1111 /$ imm. 12630

136. Tkach M, Thery C. Communication by extracellular vesicles: where we are and where we need to go. Cell (2016) 164:1226-32. doi: 10.1016/j.cell.2016.01.043

137. Morelli AE, Larregina AT, Shufesky WJ, Sullivan ML, Stolz DB, Papworth GD, et al. Endocytosis, intracellular sorting, and processing of exosomes by dendritic cells. Blood (2004) 104:3257-66. doi: 10.1182/blood-2004-03-0824

138. Saunderson SC, Dunn AC, Crocker PR, McLellan AD. CD169 mediates the capture of exosomes in spleen and lymph node. Blood (2014) 123:208-16. doi: 10.1182/blood-2013-03-489732

139. Black LV, Saunderson SC, Coutinho FP, Muhsin-Sharafaldine MR, Damani TT, Dunn AC, et al. The CD169 sialoadhesin molecule mediates cytotoxic $\mathrm{T}$ cell responses to tumour apoptotic vesicles. Immunol Cell Biol. (2015) 94:430-38 doi: 10.1038/icb.2015.111

140. Pucci F, Garris C, Lai CP, Newton A, Pfirschke C, Engblom C, et al. SCS macrophages suppress melanoma by restricting tumor-derived vesicle-B cell interactions. Science (2016) 352:242-6. doi: 10.1126/science.aaf1328

141. Ohnishi K, Komohara Y, Saito Y, Miyamoto Y, Watanabe M, Baba H, et al. CD169-positive macrophages in regional lymph nodes are associated with a favorable prognosis in patients with colorectal carcinoma. Cancer Sci. (2013) 104:1237-44. doi: $10.1111 /$ cas.12212 
142. Saito Y, Ohnishi K, Miyashita A, Nakahara S, Fujiwara Y, Horlad H, et al. Prognostic significance of $\mathrm{CD} 169^{+}$lymph node sinus macrophages in patients with malignant melanoma. Cancer Immunol Res. (2015) 3:1356-63. doi: 10.1158/2326-6066.CIR-14-0180

143. Ohnishi K, Yamaguchi M, Erdenebaatar C, Saito F, Tashiro H, Katabuchi HT, et al. Prognostic significance of CD169-positive lymph node sinus macrophages in patients with endometrial carcinoma. Cancer Sci. (2016) 107:846-52. doi: 10.1111/cas.12929

144. Shiota T, Miyasato Y, Ohnishi K, Yamamoto-Ibusuki M, Yamamoto Y, Iwase $\mathrm{H}$, et al. The clinical significance of CD169-positive lymph node macrophage in patients with breast cancer. PLoS ONE (2016) 11:e0166680. doi: 10.1371/journal.pone.0166680

145. Asano T, Ohnishi K, Shiota T, Motoshima T, Sugiyama Y, Yatsuda J, et al. CD169-positive sinus macrophages in the lymph nodes determine bladder cancer prognosis. Cancer Sci. (2018) 109:1723-30. doi: 10.1111/cas. 13565

146. Delputte PL, Van Gorp H, Favoreel HW, Hoebeke I, Delrue I, Dewerchin $\mathrm{H}$, et al. Porcine sialoadhesin (CD169/Siglec-1) is an endocytic receptor that allows targeted delivery of toxins and antigens to macrophages. PLoS ONE (2011) 6:e16827. doi: 10.1371/journal.pone.0016827

147. Ooms K, Van Gorp H, Botti S, Van Gaever T, Delputte PL, Nauwynck HJ. Evaluation of viral peptide targeting to porcine sialoadhesin using a porcine reproductive and respiratory syndrome virus vaccinationchallenge model. Virus Res. (2013) 177:147-55. doi: 10.1016/j.virusres.2013. 07.019

148. Chen WC, Kawasaki N, Nycholat CM, Han S, Pilotte J, Crocker $\mathrm{PR}$, et al. Antigen delivery to macrophages using liposomal nanoparticles targeting sialoadhesin/CD169. PLoS ONE (2012) 7:e39039. doi: 10.1371/journal.pone.0039039

149. Kawasaki N, Vela JL, Nycholat CM, Rademacher C, Khurana A, van Rooijen N, et al. Targeted delivery of lipid antigen to macrophages via the CD169/sialoadhesin endocytic pathway induces robust invariant natural killer T cell activation. Proc Natl Acad Sci USA. (2013) 110:7826-31. doi: 10.1073/pnas. 1219888110

150. Gaya M, Barral P, Burbage M, Aggarwal S, Montaner B, Warren Navia A, et al. Initiation of antiviral B cell immunity relies on innate signals from spatially positioned NKT cells. Cell (2018) 172:517-33.e20. doi: 10.1016/j.cell.2017.11.036

151. Yu X, Feizpour A, Ramirez NG, Wu L, Akiyama H, Xu F, et al. Glycosphingolipid-functionalized nanoparticles recapitulate CD169dependent HIV-1 uptake and trafficking in dendritic cells. Nat Commun. (2014) 5:4136. doi: 10.1038/ncomms5136

Conflict of Interest Statement: The authors declare that the research was conducted in the absence of any commercial or financial relationships that could be construed as a potential conflict of interest.

Copyright (C) 2018 Grabowska, Lopez-Venegas, Affandi and den Haan. This is an open-access article distributed under the terms of the Creative Commons Attribution License (CC BY). The use, distribution or reproduction in other forums is permitted, provided the original author(s) and the copyright owner(s) are credited and that the original publication in this journal is cited, in accordance with accepted academic practice. No use, distribution or reproduction is permitted which does not comply with these terms. 